\title{
Analysis of HLA-D Micropolymorphism by a Simple Procedure: RNA Oligonucleotide Hybridization
}

\author{
Catherine Ucla, Jon J. van Rood, Jack Gorski, and Bernard Mach \\ Department of Microbiology, University of Geneva School of Medicine, Geneva, Switzerland
}

\begin{abstract}
Recent progress in the molecular genetics of HLA class II antigens has revealed the existence of multiple loci and of a large degree of polymorphism, with more individual alleles than was expected. An accurate detection and analysis of this extensive polymorphism is essential for optimal HLA typing for transplantation and for a reevaluation of HLA-disease association. Because of the limitations of the current typing methods, including restriction fragment length polymorphisms, we have proposed a DNA typing procedure based on hybridization with loci- and allele-specific oligonucleotides. Here we present a much simpler way of analyzing class II micropolymorphism down to the level of single nucleotide differences. RNA oligonucleotide typing (ROT) relies on RNA dot blots and requires $10-20 \mathrm{ml}$ of blood. It is shown that with appropriate oligonucleotide probes, ROT can reliably and unambiguously identify any polymorphism at any of the HLA loci, including new alleles, not identified with previous methods. This illustrates the importance of oligonucleotide typing to optimize HLA matching, in particular for transplantation involving unrelated donors.
\end{abstract}

\section{Introduction}

HLA class II molecules are transmembrane glycoproteins formed of an $\alpha$ - and a $\beta$-chain. They are involved in the presentation of antigens to $T$ lymphocytes and are therefore essential in the development of an immune response $(1,2)$. HLA class II molecules are characterized by an extensive allelic polymorphism and by a great genetic complexity, with a number of distinct $\alpha$ - and $\beta$-chain loci. In man, one recognizes three subregions, DP, DQ, and DR, encoding distinct $\alpha / \beta$ dimers $(3,4)$. As many as $15 \alpha$ - or $\beta$-chain genes have been identified (see review in 5) and in the case of HLA-DR, at least three polymorphic $\beta$-chain loci have been mapped, two of which are expressed into distinct DR $\beta$-chains (6).

The importance of the HLA class II polymorphism in organ transplantation and in the association of HLA with several diseases emphasizes the need for a reliable analysis of this

Address reprint requests to Dr. Mach, Department of Microbiology, University of Geneva Medical School, CMU, 1211 Geneva. Dr. van Rood was on leave from University Hospital, Department of Immunohaematology \& Bloodbank, Leiden, The Netherlands.

Received for publication 19 February 1987 and in revised form 5 June 1987

J. Clin. Invest.

(c) The American Society for Clinical Investigation, Inc.

0021-9738/87/10/1155/05 \$2.00

Volume 80, October 1987, 1155-1159 polymorphism. Serological typing, cellular assays, and biochemical studies of the polypeptide products have been used for most of the HLA-D region loci (4). However, since molecular genetic studies have shown that the number of individual class II loci and the number of alleles at these loci are in fact greater than had been previously detected (5), there is clearly a need for more sensitive procedures, capable of analyzing the fine specificity of individual loci and alleles. This is becoming especially important to improve the fine HLA matching of graft recipients and unrelated bone marrow donors. The availability of cloned HLA class II genes has allowed the development of a new approach referred to as "HLA DNA typing," based on DNA-DNA hybridization and on the polymorphism of restriction fragment length (7). The large number of distinct restriction fragment length polymorphism (RFLP) ${ }^{1}$ patterns has shown the power of such a direct approach to genotyping (7-12). The procedure however is limited to polymorphic restriction sites, and to a large extent it only reflects polymorphic variations outside of the gene coding regions.

The availability of DNA sequence information for the polymorphic HLA DR $\beta$-chain $(13,14)$ has revealed some of the mechanisms involved in the generation of the DR polymorphism, such as duplication, gene conversion, and recombination $(5,15)$. These structural data have also lead us to propose an alternative approach to HLA genotyping: synthetic oligonucleotides, corresponding to specific variable regions of the class II genes can be used as hybridization probes for a direct analysis of phenotypically relevant polymorphism at the DNA sequence level (16). This procedure is now being used not only to refine HLA typing beyond the capabilities of other procedures including RFLP, but also to establish correlations between individual DNA segments and the functional or serological specificities of individual class II gene products.

DNA oligonucleotide typing (DOT), as described by Angelini et al. (16), is sensitive, accurate, and informative. However, it requires the preparation of DNA and the electrophoretic fractionation of restriction enzyme-digested DNA before hybridization. Indeed many oligonucleotide probes hybridize, as expected, to one or more other non-HLA and nonpolymorphic bands. These can easily be distinguished on an electrophoretic blot (16) but not with a simpler dot blot procedure. Consequently, total genomic DNA cannot be analyzed by dot blot hybridization for oligonucleotide HLA typing. To take advantage of the greater simplicity of RNA preparations and of the rapid and simple dot blot procedure, we have developed a new HLA-typing method based on allele and loci-specific oligonucleotide hybridization to RNA dot blots (RNA oligonucleotide typing, or ROT).

1. Abbreviations used in this paper: DOT, DNA oligonucleotide typing; PBL, peripheral blood leukocytes; RFLP, restriction fragment length polymorphism; ROT, RNA oligonucleotide typing. 


\section{Methods}

Synthesis of oligonucleotides. Oligonucleotide probes were synthesized using a gene-assembler (Pharmacia Fine Chemicals, Piscataway, NJ) or were provided by E. Kawashima (Biogen SA, Geneva, Switzerland). They were purified by electrophoresis through an acrylamide-urea sequencing gel (17). The sequence and the origin of the oligonucleotides used in this study are presented in Fig. 1.

${ }^{32} P$ Labeling of oligonucleotides. Gel-purified oligonucleotides (19 mers) were end labeled with ${ }^{32} \mathrm{P}$ using polynucleotide kinase, as described before (16). They were then purified by chromatography on a DE-52 cellulose column. The specific activity of the probes was $\sim 2$ $\times 10^{9} \mathrm{cpm} / \mu \mathrm{g}$.

Cell lines and blood samples. We used $0.5-1 \times 10^{8}$ cells from the following Epstein-Barr virus (EBV) transformed cell lines: Mal 1 (HLA-DR4, Drw53), QBL (HLA DR3, DRw52, DQw2, DP2), AVL (HLA-DR3, DRw52, DQw2, DP4), DR4/6 (HLA-DR4, DRw6, DRw52, DRw53). We also used lymphocytes (Ficoll-Isopaque isolated) from $20 \mathrm{ml}$ heparinized blood from volunteer donors (HLA typed at the United d'Immunologie de Transplantation, Hôpital Cantonal, Geneva, by Dr. M. Jeannet).

Preparation and blotting of RNA. RNA was prepared from cell pellets (fresh or frozen) using the guanidine isothiocyanate/ $\mathrm{CsCl}$ gradient procedure (18). Northern blots were prepared following glyoxal denaturation as described (19), using Gene-Screen plus membranes (Dupont Corp., Wilmington, DE). RNA was spotted either by hand or with a minifold $\mathbf{R}_{\mathbf{I I}}$ (Schleicher \& Schüell, Keene, NH) onto Pall Biodyne membranes (Pall Corporation, Glen Cove, NY).

Hybridization. Prehybridization and hybridization were done at $50^{\circ} \mathrm{C}$ as described elsewhere (16), using $7 \%$ sodium dodecyl sulfate (SDS) buffer. Hybridization was for $16 \mathrm{~h}$. Washing was done using the protocol described for DNA oligonucleotide typing (16), except that the washing temperature was previously optimized. All oligos used in this study required $50^{\circ} \mathrm{C}$ except for oligo 3 , which requires $52^{\circ} \mathrm{C}$. Autoradiography was done using preflashed Kodak X-AR5 films with a Cawo SEG intensifying screen at $-70^{\circ} \mathrm{C}$ for $2 \mathrm{~d}$.

\section{Results}

Control hybridization by Northern blots. When oligonucleotides are used with genomic DNA, they frequently hybridize to one or more additional DNA fragment, unrelated to HLA (16). This is expected from the size of the oligomers (19-mers) and the complexity of the mammalian genome. This phenomenon does not prevent the use of oligonucleotides on electrophoretic blots of restricted DNA (16), but it makes it impossi-

DR B LOCI (FIRST DOMAIN)

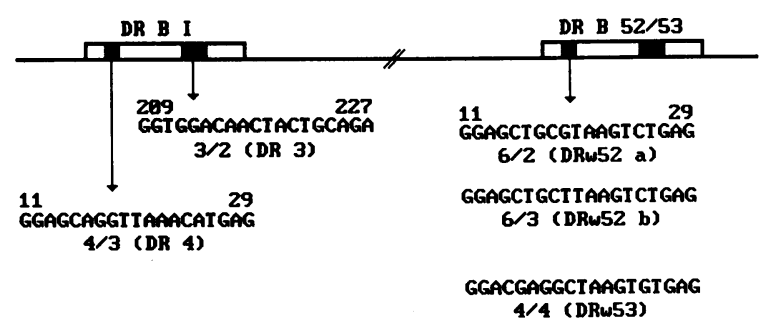

Figure 1. The oligonucleotide probes and their specificity. The schematic representation of the two expressed loci in DRw52 or DRw53 haplotypes includes the position (hatched areas) from which these oligonucleotides were derived (specified by the position in base pair along the DNA sequence). Each oligonucleotide is identified by a number and by the allelic specificity of individual probes. The DNA sequences are derived from references 15 and 20. ble to use the simpler dot blot approach with genomic DNA samples. The use of RNA circumvents this problem, but oligo probes must be controlled for their unique hybridization to class II mRNA. This is shown in Fig. 2 and all probes used in this study do show this unique pattern and consequently can be used for RNA dot blot hybridization.

An important additional control is shown on Fig. 2, where the RNA from two DR3 homozygous lines (AVL and QBL) is analyzed. We have shown by DNA sequence analysis that these two cells differ at their DR BIII (DRw52) locus, where one finds, respectively, the DRw52a and DRw52b alleles (6, $16,20)$. The 52a and 52b oligonucleotides differ by only one out of 19 nucleotides and there is complete discrimination in the RNA hybridization (Fig. 2), as is the case in hybridizations to DNA (16).

As is evident from a recent report (21), oligonucleotide hybridization to dried gels (22) is less favorable in terms of background, sensitivity and ease of interpretation than the membrane filters procedure presented earlier in reference 16 and used in this paper.

Hybridization to RNA dot blots. We next examined if a DR $\beta$-chain hybridization signal could be obtained with oligonucleotides on total RNA spotted on membrane filters. Fig. 3 shows first that the sensitivity is such that $1 \mu \mathrm{g}$ of total RNA allows the detection of the specific sequence from each of the two individual DR loci. Second, this figure also shows that the sequence specificity and the discrimination is maintained upon slot blot hybridization. Finally, the experiment shown in Fig. $3 B$ indicates that RNA prepared from blood samples can also allow the detection of allele and loci-specific signals with oligonucleotides. The amount of RNA routinely obtained from peripheral blood leukocytes (PBLS) from $20 \mathrm{ml}$ of blood (20-40 $\mu \mathrm{g}$ ) allows the spotting of 20-40 RNA samples and therefore makes possible the simultaneous analysis with a large number of allele-specific oligonucleotides. Dehybridization and rehybridization can be performed at least three times with only minimal losses in signal strength (data not shown), so

\begin{tabular}{|c|c|}
\hline $\begin{array}{c}\text { oligo 6/2 } \\
(52 a)\end{array}$ & $\begin{array}{c}\text { oligo } 6 / 3 \\
(52 b)\end{array}$ \\
\hline$\frac{1}{4}$ & $\stackrel{1}{0}$ \\
\hline
\end{tabular}

Figure 2. Northern blot hybridization with two oligonucleotide probes differing by a single nucleotide. The DR3 homozygous cell lines AVL and QBL are, respectively, DR52a and DRw52b from the DNA sequence of the DR BIII supertypic locus $(15,16$, and unpublished). Their RNA hybridizes to oligonucleotide $6 / 2$ and $6 / 3$, which are specific for DRw52a and DRw52b, respectively (16). 
Table I. Oligo-typing with 5 Oligonucleotide Probes

\begin{tabular}{|c|c|c|c|c|c|c|c|c|}
\hline \multirow[b]{2}{*}{ Samples } & \multicolumn{5}{|c|}{ Oligonucleotides } & \multicolumn{2}{|l|}{ Oligo-typing } & \multirow[b]{2}{*}{ DR specificity } \\
\hline & $3 / 2$ & $4 / 3$ & $6 / 2$ & $6 / 3$ & $4 / 4$ & locus $\beta \mathrm{I}$ & locus $\beta 52 / 53$ & \\
\hline 1 & - & - & - & + & - & $(5 / w 6)$ & $52 b$ & DR5; DRw6 \\
\hline 2 & - & + & - & + & + & $\begin{array}{l}4 \\
(5 / w 6)\end{array}$ & $\begin{array}{l}53 \\
52 b\end{array}$ & DR4; DR5 \\
\hline 3 & - & - & + & - & - & $(5 / w 6)$ & $52 a$ & DRw6; DR8 \\
\hline 4 & + & - & + & + & - & $\begin{array}{l}3 \\
(3 / 5 / w 6)\end{array}$ & $\begin{array}{l}52 a \\
52 b\end{array}$ & DR3; DR5 \\
\hline 5 & - & + & - & + & + & $\begin{array}{l}4 \\
(5 / w 6)\end{array}$ & $\begin{array}{l}53 \\
52 \mathrm{~b}\end{array}$ & DR4; DRw6 \\
\hline 6 & - & - & - & - & + & 7 & 53 & DR7/- \\
\hline 7 & ND & + & - & - & + & 4 & 53 & DR4; DR7 \\
\hline 8 & ND & + & - & + & + & $\begin{array}{l}4 \\
(5 / w 6)\end{array}$ & $\begin{array}{l}53 \\
52 b\end{array}$ & DR4; DRw6 \\
\hline 9 & - & - & ND & ND & + & 7 & 53 & DR7; DR9 \\
\hline
\end{tabular}

Summary of the hybridization results of Fig. 4. Hybridization with individual oligonucleotide probes is indicated by + or - . The deduced DR allele for locus $\beta \mathrm{I}$ or $\beta \mathrm{III}$ is indicated (with alternative possibilities in parentheses). The serological DR specificities are listed in the last column.

that, if required, a single RNA preparation from $20 \mathrm{ml}$ of blood could be tested with 60 or more different oligonucleotides.

$R N A$ hybridization of individual donors with five oligonucleotides. We next prepared RNA from $20 \mathrm{ml}$ of blood from a number of HLA typed volunteers and prepared RNA slot blots. They were hybridized with five oligonucleotides, defining, respectively, the specificities DR3, DR4, DRw52a, DRw52b, and DRw53. Fig. 4 shows that the radioautographs can unequivocally be interpreted as a positive or negative hybridization. This limited series, which utilized only five probes, demonstrates that the identification of specific alleles at individual loci can be achieved with total RNA with a sensitivity and a resolution down to the level of a single nucleotide. It is
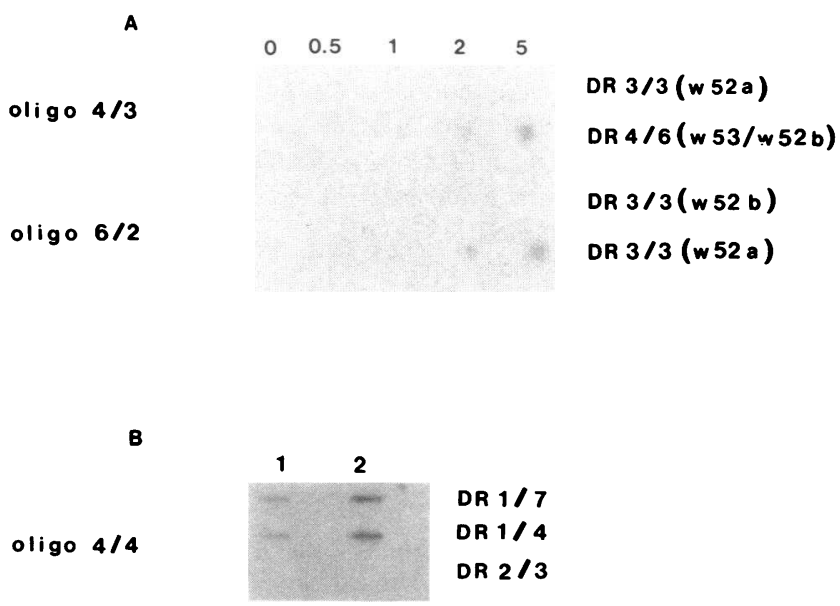

Figure 3. Controls for RNA spot test hybridization with oligonucleotides. $(A)$ Total RNA from B cell lines (DR specificities indicated) is spotted at different concentrations (amount of RNA indicated in micrograms). Two oligonucleotides, 4/3 (DR4) and 6/2 (DRw52a), are used as probes. $(B)$ RNA prepared from blood samples $(\mathrm{PBL})$ is spotted at 1 and $2 \mu \mathrm{g}$ as indicated. A DRw53 specific oligonucleotide $(4 / 4)$ is used as a probe. obvious that five probes are not sufficient for a complete DR typing and that the use of additional sequence-specific oligonucleotides in the same kind of analysis could provide an extensive HLA typing, beyond the specificity of current procedures. More importantly, Fig. 4 illustrates a case where two alleles of a given DR locus, 52a and 52b, cannot be typed by other procedures, and yet can easily be identified with specific oligonucleotides.

\section{Discussion}

HLA class II typing is essential for optimal matching in organ transplantation and it is of great importance in the understanding of associations between disease susceptibility and HLA class II specificities. Typing of HLA class II determinants has been possible since 1973 in man (23) and mouse (24-26). In man, cellular (27-30) and serological $(23,31)$ techniques were developed simultaneously. The somewhat cumbersome

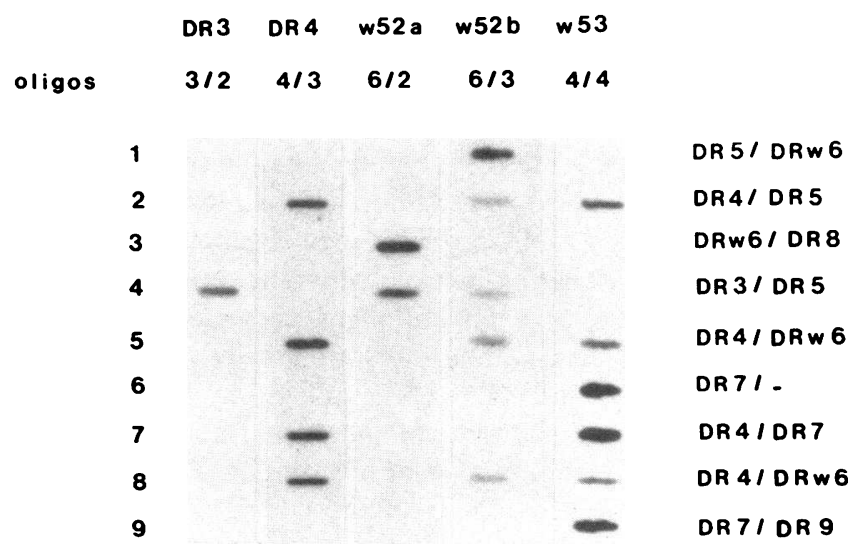

Figure 4. Hybridization with five distinct allele and loci-specific oligonucleotide probes. RNA prepared from $10 \mathrm{ml}$ of blood of nine volunteers was spotted at $3 \mu \mathrm{g} / \mathrm{slot}$. The identity of the five oligonucleotides is indicated above and the serological specificity of the individual donors is indicated on the right. 
cellular techniques were soon largely, although never completely, replaced by serological methods using different variants of the complement dependent cytotoxicity test $(32,33)$. Although the first studies suggested that cellular and serological techniques might be recognizing the same determinants, it soon became clear that some of the differences were real and that cellular techniques were able to distinguish more allelomorphic forms than had been possible thus far with serology (34).

Two important findings have emerged from the recent molecular structural studies of HLA class II genes (see review in 5). The number of HLA class II genes is greater than had been anticipated and the degree of allelic polymorphism identified at the level of DNA sequences implies a greater number of distinct alleles $(5,15)$. New HLA typing procedures should therefore aim at a better discrimination among the different alleles at each of the individual loci.

The possibility of identifying individual HLA class II specificities directly at the DNA level by hybridization to restriction enzyme digested DNA (7) has represented a major improvement toward a more sensitive typing. However, HLA typing by RFLP is limited to polymorphic variations that affect restriction enzyme sites and to a large extent these sites concern noncoding regions that are not phenotypically relevant. We have therefore proposed a different approach to HLA genotyping, based on DNA sequences and which makes use of loci and allele-specific oligonucleotides as hybridization probes (16). DNA oligonucleotide typing (DOT) can distinguish among alleles differing by as little as a single nucleotide (16) and the procedure analyzes each expressed HLA-D locus individually, including the two nonallelic HLA-DR $\beta$-chain loci $(6,15,16)$.

To simplify the DOT procedure without loss of accuracy, we have then considered the use of dot blot (or slot blot) oligonucleotide hybridization. With total genomic DNA however, oligonucleotide probes often hybridize to additional non-major histocompatibility complex (MHC) DNA fragments and this obviously precludes the use of the dot blot approach, unless one introduces in the DOT procedure an amplification step as recently proposed $(35,36)$. We have therefore performed hybridizations directly on RNA of class II positive cells. It is obvious from the data presented here that RNA prepared from blood lymphocytes can be used directly, without amplification, in a very simple dot blot hybridization procedure for an accurate identification of all allelic specificities for which DNA sequence information is available. This paper reports on the use of only five oligonucleotide probes, and with these probes, the corrolation with serological typing is complete. As more DNA sequence data becomes available, one can anticipate that an exhaustive typing protocol will be feasible with the use of a panel of oligonucleotides.

In addition to the advantage of simplicity of this new procedure, oligonucleotide HLA typing allows the identification of allelic series for which there is no other assays short of DNA sequencing. The demonstration of oligonucleotide typing for newly recognized alleles at the DRw52 locus, 52a and 52b, (16, and this study) is an example of this discrimination in HLA typing. By the same token, oligonucleotide typing is becoming the method of choice for other loci for which conventional typing is limited to broad specificities, such as DP or DQ (unpublished results). It is clear that many of the short and subtle sequence differences that determine the different forms of graft rejection or mixed lymphocyte reactions (MLR) will not be identified with serological or cellular typing, nor with protein biochemistry or RFLP. This capacity to analyze HLA micropolymorphism down to the level of single nucleotide changes, should allow to predict a negative MLR, to identify differences not even detected by MLR and could well become essential in the context of more accurate HLA class II matching for bone marrow transplantation with unrelated donors. Compared with DNA oligonucleotide typing (16), including with the incorporation of the elegant amplification step recently reported $(35,36)$, the RNA oligonucleotide typing procedure described here is more economical and it analyzes selectively expressed and phenotypically relevant genes.

DNA oligonucleotide typing, DOT (16), whether on Southern blots or on amplified DNA (35), and ROT (this study), makes the identification of alleles for all HLA class II loci down to the level of DNA sequence a realistic objective. The methodology is easily adaptable to a very large scale and to routine use. As more DNA sequence information becomes available, this new and very simple approach will become a crucial tool in HLA matching for organ transplantation.

\section{Acknowledgments}

We are grateful to S. Fey for technical assistance and to J. Berdoz and I. Amaldi for advice.

This work was supported by the Swiss National Foundation for Scientific Research.

\section{References}

1. Benacerraf, B., and R. N. Germain. 1978. The immune response genes of the major histocompatibility complex. Immunol. Rev. 38:70119.

2. Munro, A. J., and H. Waldmann. 1978. The histocompatibility system and the immune response. Br. Med. Bull. 34:253-258.

3. Histocompatibility Testing 1980. P. I. Terasaki, editor. Los Angeles, UCLA Tissue Lab.

4. Histocompatibility Testing 1984. E. D. Albert, M. P. Baur, and W. R. Mayr, editors. Springer Verlag, Berlin.

5. Mach, B., J. Gorski, P. Rollini, C. Berte, I. Amaldi, Berdoz, and C. Ucla. 1986. Polymorphism and regulation of HLA class II genes of the major histocompatibility complex. Cold Spring Harbor Symp. Quant. Biol. 51:67-74.

6. Rollini, P., B. Mach, and J. Gorski. 1985. Linkage map of three HLA-DR bêta-chain genes. Evidence for a recent duplication event. Proc. Natl. Acad. Sci. USA. 82:7197-7201.

7. Wake, C. T., E. O. Long, and B. Mach. 1982. Allelic polymorphism and complexity of the genes for HLA-DR $\beta$ chains-direct analysis by DNA-DNA hybridization. Nature (Lond.). 300:372-374.

8. Cohen, D., P. Paul, I. Le Gall, A. Marcadet, M. P. Font, O. Cohen-Haguenauer, B. Sayagh, H. Cann, J. M. Lalouel, and J. Dausset. 1985. DNA polymorphism of HLA class I and class II regions. Immunol. Rev. 85:87-105.

9. Kim, S. E., S. L. Holbeck, B. Nisperos, J. A. Hansen, H. Maeda, and G. T. Nepom. 1985. Identification of a polymorphic variant associated with HLA-DQw3 and characterized by specific restriction sites within the DQ $\beta$-chain gene. Proc. Natl. Acad. Sci. USA. 82:81398143.

10. Tilanus, M. G. J., B. Morolli, M. C. J. A. Van Eggermond, G. M. Th. Schreier, R. R. P. de Vries, and M. J. Giphart. 1986. Dissection of HLA class II haplotypes in HLA-DR4 homozygous individuals. Immunogenetics. 23:333-340.

11. Hitman, G. A., J. Sachs, P. Cassell, J. Awad, G. F. Bottazzo, A. C. Tarn, G. Schwartz, J. P. Monson, and H. Festentein. 1986. A 
DR3-related $\mathrm{DX}_{\mathrm{L}}$ gene polymorphism strongly associates with insulin-dependent Diabetes melitus. Immunogenetics. 23:47-51.

12. Inoko, H., A. Ando, K. Tsuji, K. Matsuki, K. Juji, and Y. Honda. 1986. HLA-DQ $\beta$ chain DNA restriction fragments can differentiate between healthy and narcoleptic individuals with HLADR2. Immunogenetics. 23:126-128.

13. Long, E. O., C. T. Wake, J. Gorski, and B. Mach. 1983. Complete sequence of an HLA-DR $\beta$ chain deduced from a cDNA clone and identification of multiple non-allelic DR $\beta$ chain genes. EMBO J. 2:389-394.

14. Gustafsson, K., K. Wiman, E. Emmoth, D. Larhammar, J. Böhme, J. J. Hyldig-Nielsen, H. Ronne, P. Peteron, and L. Rask. 1984. Mutation and selection in the generation of class II histocompatibility antigen polymorphism. EMBO J. 3:1655-1661.

15. Gorski, J., and B. Mach. 1986. Polymorphism of human Ia antigens: gene conversion between two DR $\beta$ loci results in a HLA-D/ DR specificity. Nature (Lond.). 322:67-70.

16. Angelini, G., C. de Préval, J. Gorski, and B. Mach. 1986. High-resolution analysis of the human HLA-DR polymorphism by hybridization with sequence-specific oligonucleotide probes. Proc. Natl. Acad. Sci. USA. 83:4489-4493.

17. Maxam, A. M., and W. Gilbert. 1977. A new method for sequencing DNA. Proc. Natl. Acad. Sci. USA. 74:560-564.

18. Chirgwin, J. M., A. E. Przybyla, R. J. MacDonald, and W. J. Rutter. 1979. Isolation of biologically active ribonucleic acid from sources enriched in ribonuclease. Biochemistry. 18:5294-5299.

19. Thomas, P. 1980. Hybridization of denatured RNA and small DNA fragments transferred to nitrocellulose. Proc. Natl. Acad. Sci. USA. 77:5201-5205.

20. Gorski, J., P. Rollini, and B. Mach. 1987. Structural comparison of the genes of two HLA-DR supertypic groups: the loci encoding DRW52 and DRW53 are not truly allelic. Immunogenetics. 25:937402.

21. Le Gall, I., P. Millasseau, J. Dausset, and D. Cohen. 1986. Two DR $\beta$ allelic series defined by exon II-specific synthetic oligonucleotide genomic hybridization: a method of HLP typing? Proc. Natl. Acad. Sci. USA. 83:7836-7840.

22. Conner, B. J., A. A. Reyes, C. Morin, K. Itakura, R. L. Teplitz, and R. B. Wallace. 1983. Detection of Sickle cell $\beta^{\mathrm{S}}$-globin allele by hybridization with synthetic oligonucleotides. Proc. Natl. Acad. Sci. USA. 80:278-282.

23. van Leeuwen, A., H. R. E. Schuit, and J. J. van Rood. 1973. Typing for MLC (LD): II. The selection of non-stimulator cells by MLC inhibition tests using SD-identical stimulator cells (MISIS) and fluorescence antibody studies. Transplant. Proc. 5:1539-1542.

24. Hauptfeld, V., D. Klein, and J. Klein. 1973. Serological identification of an Ir-region product. Science (Wash. DC). 181:167-169.
25. Shreffler, D., C. David, D. Götze, J. Klein, H. McDevitt, and D. Sachs. 1974. Genetic nomenclature for new lymphocyte antigens controlled by the I region of the H-2 complex. Immunogenetics. 1:189190.

26. Andersson, L. C., and P. Häyry. 1973. Specific priming of mouse thymus dependent lymphocytes to allogenic cells in vitro. Eur. J. Immunol. 3:595-599.

27. van den Tweel, J. G., A. Blussé van Oud Alblas, J. J. Keuning, E. Goulmy, A. Termijtelen, M. L. Bach, and J. J. van Rood. 1973. Typing for MLC (LD). I. Lymphocytes from cousin marriages offsprings as typing cells. Transplant. Proc. 5:1535-1538.

28. Mempel, W., H. Grosse-wilde, P. Baumann, B. Netzel, I. Steinbauer-Rosenthal, S. Scholz, J. Bertrams, and E. D. Albert. 1973. Population genetics of the MLC response: typing for MLC determinants using homozygous and heterozygous reference cells. Transplant. Proc. 5:1529-1534.

29. Bach, F. H., P. M. Sondel, M. J. Sheehy, R. Wank, B. J. Alter, and M. L. Bach. 1975. The complexity of the HLA-LD system: a PLT analysis. In Histocompatibility Testing 1975. F. Kissmeyer-Nielsen, editor. Copenhagen, Munksgaard. 576-580.

30. Mawas, C. E., D. Charmot, and M. Sasportes. 1975. Secondary response of in vitro primed human lymphocytes to allogenic cells. I. Role of HLA-A antigens and mixed lymphocyte reaction stimulating determinants in secondary in vitro proliferative response. Immunogenetics. 2:449-463.

31. van Leeuwen, A., R. J. Winchester, and J. J. van Rood. 1975. Serotyping for MLC II. Technical aspects. Ann. NY Acad. Sci. 254:289-295.

32. van Rood, J. J., A. van Leeuwen, J. J. Keuning, and A. Blussé van Oud Alblas. 1975. The serological recognition of the human MLC determinants using a modified cytotoxicity technique. Tissue Ant. 5:73-79.

33. van Rood, J. J., A. van Leeuwen, and J. S. Ploem. 1976. Simultaneous detection of two cell populations by two-colour fluorescence and application to the recognition of B-cell determinants. Nature (Lond.). 262:795-797.

34. Bodmer, W. F., E. D. Albert, J. G. Bodmer, J. Dausset, F. Kissmeyer-Nielsen, W. Mayr, R. Payne, J. J. van Rood, Z. Trnka, and R. L. Walford. 1984. Nomenclature for factors of the HLA system. 1984. Hum. Immunol. 11;117-125.

35. Faloona, F. A., and K. B. Mullis. 1987. Specific synthesis of DNA in vitro via a polymerase catalyzed chain reaction. In Methods in Enzymology. Academic Press, Orlando, FL. Vol. 155. In press.

36. Saiki, R. K., T. L. Bugawan, G. T. Horn, K. B. Mullis, and H. A. Erlich. 1986. Analysis of enzymatically amplified $\beta$-globin and HLA-DQ $\alpha$ DNA with allele-specific oligonucleotide probes. Nature (Lond.). 324:163-166. 